\title{
Power-relational core-periphery structures: Peripheral dependency and core dominance in binary and valued networks
}

Carl Nordlund

The self-archived postprint version of this journal article is available at Linköping University Institutional Repository (DiVA):

http:// urn.kb.se/ resolve?urn=urn:nbn:se:liu:diva-153113

N.B.: When citing this work, cite the original publication.

Nordlund, C., (2018), Power-relational core- periphery structures: Peripheral dependency and core dominance in binary and valued networks, Network Science, 6(3), 348-369.

https:// doi.org/ 10.1017/ nws.2018.15

Original publication available at:

https:// doi.org/ 10.1017/ nws.2018.15

Copyright: Cambridge University Press (CUP) (HSS J ournals)

http:/ / www.cambridge.org/ uk/ 


\title{
Power-relational core-periphery structures: peripheral dependency and core dominance in binary and valued networks
}

\author{
Pre-published version of
}

Nordlund, C. 2018. Power-relational core-periphery structures: Peripheral dependency and core dominance in binary and valued networks, Network Science, 6(3), pp. 348-369.

https://doi.org/10.1017/nws.2018.15

Carl Nordlund ${ }^{1,2,3}$

carl.nordlund@liu.se

${ }^{1}$ Institute for Analytical Sociology, Linköping university, Sweden

${ }^{2}$ Center for Network Science, Central European University, Hungary

${ }^{3}$ Department of Economic History, Lund university, Sweden

\section{Abstract}

With origins in post-war development thinking, the core-periphery concept has spread across the social and, increasingly, the natural sciences. Initially reflecting divergent socioeconomic properties of geographical regions, its relational connotations rapidly led to more topological interpretations. In today's network science, the standard core-periphery model consists of a cohesive set of core actors and a peripheral set of internally disconnected actors.

Exploring the classical core-periphery literature, this paper finds conceptual support for the characteristic intra-categorical density differential. However, this literature also lends support to the notions of peripheral dependency and core dominance, power-relational aspects that existing approaches do not capture.

To capture such power-relations, this paper suggests extensions to the correlation-based core-periphery metric of Borgatti-Everett (2000). Capturing peripheral dependency and, optionally, core dominance, these extensions allow for either measuring the degree of such power-relational features in given coreperiphery partitions, or as part of a criteria function to search for power-relational core-periphery structures.

Applied to the binary and valued citation data in Borgatti and Everett (2000), the proposed extensions seemingly capture dependency and dominance features of core-periphery structures. This is particularly evident when, circling back to to the original domains of the concept, examining the network of European commodity trade in 2010.

\section{Keywords}

Core-periphery, History of ideas, Economic history, Peripheral dependency, Core dominance 


\section{Introduction}

The origin of "center/core", "periphery" and their coupling into the conjoint concept of repute, stems from the work of Raul Prebisch (1950) (Janvry, 1975; Love, 1980). Originally applied to highlight divergent socioeconomic properties of regions, the concept became integral to the heterodox strands of postwar development thinking (Chase-Dunn \& Hall, 1991; Frank, 1967; Galtung, 1971; Santos, 1970; Wallerstein, 1974). Prior to its recent entry into mainstream economics (e.g. Hojman \& Szeidl, 2008; Krugman, 1990, 1991, 1998), the core-periphery concept was anything but dormant: whether used as a descriptive, explanatory, or analytical device, as a model, structure, or process, or as something spatial, metaphorical, or something in-between, the remarkable dissemination of the core-periphery concept took it from its origins in political economy and international relations to virtually all of the social, and increasingly also the natural, sciences.

Within network science, core-periphery is a structural template whose relevance as an analytical device, similar to its raison d'être in social science at large (McKenzie, 1977, p. 55), rests on the idea that the general relationship between core and periphery is important for understanding the system as a whole. In the core-periphery metric of Borgatti \& Everett (2000), echoing the corresponding block image template in the blockmodeling tradition (Wasserman \& Faust, 1994, p. 419ff; White, Boorman, \& Breiger, 1976, pp. 742, 744), core and periphery are specified in terms of an intra-categorical density differential ${ }^{2}$, where a high frequency of ties among core actors contrasts an absence of ties among peripheral actors. With overall connectivity typically viewed as an overarching criterion for coreperiphery structures (Borgatti \& Everett, 2000, p. 382; Borgatti, Everett, \& Johnson, 2013, p. 225), the ties between the core and periphery subsets are either modeled as a density mid-way between the intracategorical extremes or, as often recommended (e.g. Borgatti \& Everett, 2000, p. 383; Boyd, Fitzgerald, $\&$ Beck, 2006, p. 167ff), ignored.

This article has two intertwined objectives. Whereas Borgatti and Everett view their seminal paper "as a starting point in a methodological debate on what constitutes a core/periphery structure" $(2000, \mathrm{p}$. 376), the current article continues this debate by exploring topological core-periphery specifications that followed Prebisch's original formulation. At odds with the claim "that the notion of a core/periphery structure has never been formally defined" (Borgatti \& Everett, 2000, p. 375), several topological core-

\footnotetext{
${ }^{1}$ Whereas "center" was used in the original formulation of Prebisch and pre-world system scholars, Wallerstein instead preferred the categorical label of "core". A similar terminological transition occurred in network analysis, where the early blockmodeling scholars preferred "center" (e.g. White, Boorman, \& Breiger, 1976, p. 742) and later scholars used "core" (e.g. Borgatti \& Everett, 2000). As I have found no functional distinction between "center" and "core" in neither of these traditions, I use these labels interchangeably.

${ }^{2}$ Node- and edge-level centrality-type metrics has also been suggested for identifying core-periphery structures, (Della Rossa, Dercole, \& Piccardi, 2013; Lee, Cucuringu, \& Porter, 2014). However, as pointed out by Borgatti and Everett, whereas core actors "are necessarily highly central as measured by virtually any measure [...] the converse is not true" (2000, p. 393; see also Lee et al., 2014, p. 4).
} 
periphery specifications are found in this literature. Whereas the notions of sparse peripheries and dense cores find support in this literature, support is also found for characteristic features at the intercategorical level, as patterns of peripheral dependency and core dominance. Such power-relational aspects of classical core-periphery thinking are not captured by existing models and metrics in network science.

Building on these findings, this paper proposes core-periphery models where the intra-categorical density differential is supplemented with criteria for dependent peripheries and dominating cores. Extending the core-periphery heuristic of Borgatti and Everett (2000), a correlation-based approach to capture peripheral dependency and, optionally, core dominance is proposed. Applicable to both binary and valued networks, the proposed extension can either be used to measure the degree of such powerrelations for given core-periphery partitions, or as part of the criteria function for finding optimal partitions.

The proposed metric for power-relational core-periphery structures is subsequently applied on example networks. Beginning with three simple networks, the example section revisits the binary and valued Baker citation data analyzed by Borgatti \& Everett (2000; Baker, 1992). Circling back to the political economy genesis of core-periphery thinking, a final example network of European commodity trade concludes this section.

A summary of the conceptual findings, suggested operationalization, and problematic areas identified from the examples concludes this article.

\section{Intra-categorical density differential: dense core, sparse periphery}

In the classical center-periphery (and centralized) block images (Breiger, Boorman, \& Arabie, 1975; Mullins, Hargens, Hecht, \& Kick, 1977; White et al., 1976), the proposed metrics of Borgatti and Everett (2000; Everett \& Borgatti, 2000) and the subsequent heuristics and algorithms for finding core-periphery structures (Boyd et al., 2006; Boyd, Fitzgerald, Mahutga, \& Smith, 2010; Muñiz \& Carvajal, 2006; Rombach, Porter, Fowler, \& Mucha, 2014), the intra-categorical density differential is the defining feature of core-periphery structures. This topological specification finds ample support in the "nonnetwork" literature on core-periphery structures, particularly in the fields of international relations and political economy (Berman, 1974, p. 4; Chan, 1982, p. 315; Dominguez, 1971, p. 176; Galtung, 1966a, p. 146, 1971, p. 89; Gleditsch, 1967, p. 369; Mullins et al., 1977, pp. 49-56). Among these, the studies of Galtung (1966a) and Gleditsch (1967) are particularly noteworthy, looking at, respectively, cold war international relations (see also Gochman \& Ray, 1979) and global air routes. In addition to the notions of a dense core and a sparse periphery, these two studies also specify the density of inter-categorical ties, modeled as mid-way between the two intra-categorical extremes (Galtung, 1966a, p. 146; Gleditsch, 1967, p. 369). Galtung and Gleditsch both find a distinct intra-categorical density differential in their 
respective datasets, as well as inter-categorical densities that are in-between the densities of intracategorical ties. ${ }^{3}$

However, whether inter-categorical ties are modeled as an in-between density or simply ignored, we would in either case be unable to identify notions of peripheral dependency and core dominance, features that were integral to how core-periphery structures were perceived in much of the literature following Prebisch.

\section{Dependency and dominance: core-periphery power-relations}

The center-periphery concept is foundational for the strand of development theory known as the dependency school (e.g. Amin, 1976; Cardoso \& Faletto, 1967; Frank, 1967; Santos, 1970). Combining Latin American structuralism with neo-Marxism, the dependency scholars differed from the former by depicting underdevelopment in the periphery as the direct result of its relationships with the center. Interaction between developed and underdeveloped regions was characteristically described as a hierarchical series of monopolistic metropole-satellite relations, in which each satellite was confined to dealing only with their respective metropole (Frank, 1967, pp. 7, 15; Santos, 1970, p. 235). Channeling profits from the many third world peasants to the few European industrialists (Frank, 1967), such monopolistic-oligopsonistic dendritic structures were perceived as the root cause for the development of underdevelopment (see also Bauer, 1954, p. 103; Condliffe, 1951, p. 816; Meier \& Baldwin, 1957, p. 332).

The core-periphery concept was an equally defining feature in the subsequent world-system perspective ${ }^{4}$ (Chase-Dunn, 1998; Wallerstein, 1974; see Oman \& Wignaraja, 1991; So, 1990). Even though the categorization of societies into respective world-system strata often is based on the internal characteristics of respective society, particularly how the international division of labor is manifested at the regional levels (e.g. Bousquet, 2012, p. 124), the notions of core dominance and peripheral

\footnotetext{
${ }^{3}$ What Galtung and Gleditsch do in these studies - categorical sorting of actors, calculation of intra- and intercategorical densities, and interpreting by comparing these densities to an ideal model (Galtung, 1966a, p. 163; Gleditsch, 1967, p. 377) - is in essence blockmodeling, predating the studies that formally labeled the approach as such.

${ }^{4}$ Evolving from dependency thinking, the world-system perspective differs from its predecessor in significant ways. First, supplementing the core and peripheral categories, the world-system perspective included a third category - the semiperiphery - reflecting a less deterministic and somewhat more dynamic world than the one typically described by dependency scholars (see Wallerstein, 1974, p. 403, 1979, p. 69). Secondly, surpassing the peripheral focus of the dependency school, the world-system perspective views the whole system of interconnected societies as the basic unit of analysis. Similarly, inspired by the "total history" of Braudel, Wallerstein also broadened the temporal horizon, extending world-system analysis back to the late $15^{\text {th }}$ century (cf. Chase-Dunn \& Hall, 1991; Gills \& Frank, 2014). In the macro-sociological world-system tradition, Chase-Dunn defines worldsystems "as intersocietal networks in which the interactions (e.g., trade, warfare, intermarriage, information) are important for the reproduction of the internal structures of the composite units and importantly affect changes that occur in these local structures." (Chase-Dunn \& Hall, 1991, p. 28).
} 
dependency are integral aspects of the world-system perspective (e.g. Chase-Dunn \& Grimes, 1995, p. 389; Gills \& Frank, 2014, p. 7; Rokkan \& Urwin, 1983; Wallerstein, 1974). With such an explicit emphasis on intersocietal relations in world-system analysis, the attribute-based definitions of worldsystem strata have been contested (e.g. Duvall, 1978, p. 59; Vanolo, 2010, p. 30), particularly in the series of blockmodeling studies of the modern world-system (e.g. Snyder \& Kick, 1979; Breiger, 1981; Nemeth \& Smith, 1985, p. 521; Smith \& White, 1992, p. 859; see Lloyd, Mahutga, \& Leeuw, 2015). Proclaiming a "natural wedding" between multi-relational blockmodeling and world-system analysis (Snyder \& Kick, 1979, p. 1123), Snyder and Kick argue that although correlations might exist between regional/country attributes and world-system strata, they "do not represent such position any more than an individual's income or education measures his or her (discrete) class position" (1979, p. 1102). Similarly, " $[\mathrm{w}]$ hen dependency is viewed as a referential context or in terms of structural position in the world-economy, the focus of the analysis is no longer on characteristics of individual countries, but on the relationships between countries" (Nemeth \& Smith, 1985, p. 522).

A formalization of the topology of peripheral dependency and core dominance as found in the dependency and world-system traditions is provided by Galtung (1971). In his structural theory of imperialism, Galtung views imperialism as a specific system of dominance, primarily but not exclusively between nations, "that splits up collectivities and relates some of the parts to each other in relations of harmony of interest, and other parts in relations of disharmony of interests, or conflict of interest." (1971, p. 81). He identifies two underlying mechanisms for imperialism - vertical interaction (e.g. unequal exchange, asymmetric interaction) and the so-called "feudal interaction structure" of coreperiphery relations, the latter facilitating occurrences of the former. Mentioning this interaction structure in earlier writings (Galtung, 1966b, 1968), his 1971 study provides a set of rules for identifying centerperiphery structures on the basis of interaction patterns between core and peripheral actors (1971, p. 89):

1. Interaction between Center and Periphery is vertical

2. Interaction between Periphery and Periphery is missing

3. Multilateral interaction involving all three is missing

4. Interaction with the outside world is monopolized by the Center, with two implications:

a. Periphery interaction with other Center nations is missing

b. Center as well as Periphery interaction with Periphery nations belonging to other Center nations is missing. (Galtung, 1971, p. 89; original italics)

Peripheral dependency - that each peripheral actor is connected to exactly one core actor - is given by the $4^{\text {th }}$ rule and sub-rules. Together with the $2^{\text {nd }}$ rule stating an internally disconnected periphery, ${ }^{5}$ the

\footnotetext{
${ }^{5}$ In his 1966 article, Galtung notes that a periphery gone cohesive is no longer part of a center-periphery structure: rather, with Marxian-Engelsian undertones, a center-periphery system "can be destroyed if the underdogs unite",
} 
peripheral dependency rule also constitutes the criterion for overall center-periphery connectivity. These rules translate into characteristic patterns of core-periphery relations as given in the visual example that Galtung provides, reproduced in Figure 1.

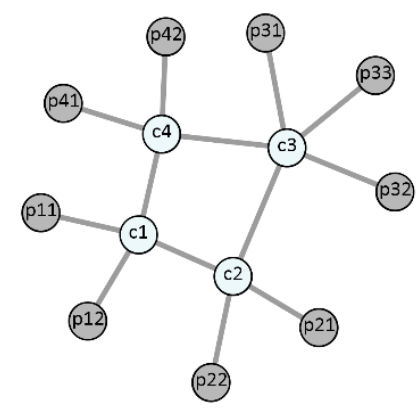

Figure 1: Center-periphery structure according to Galtung (1971, p. 89)

Galtung's rules do not specify any topological characteristics of core actors, i.e. whether it is intra-core cohesion, dominance of peripheral actors, or both, that characterize core actors. The core actors in his visual example are dominating, each having ties with unique sets of peripheries, but the rules do not explicitly rule out the existence of core actors without ties to peripheral actors. The core actors in Galtung's example are connected, but it is noteworthy that the intra-core block in his example is less than complete (density of 0.667). Although the default Borgatti-Everett core-periphery heuristic, i.e. ignoring non-diagonal blocks, applied to the Galtung example reaches the absolute maximum at the intuitive partition, the coefficient for this solution is however less than ideal (0.795). This raises the question whether k-plexes, k-cores or similarly imperfect cliques are more appropriate to describe and capture intra-core connectivity (see Everett \& Borgatti, 2000).

The notion of an intra-categorical density differential as a characteristic of core-periphery structures thus finds significant support in the 1960's literature and onwards. Concurrently, as the concept became integral to the dependency school and the subsequent world-system perspective, core-periphery relations were increasingly equated with peripheral dependency on the core and core dominance over the periphery. Despite this emphasis on such power-relations of core-periphery structures, peripheral dependency and core dominance are not part of the contemporary network-scientific conceptualization of core-periphery structures.

The next section will introduce extensions to the correlation-based core-periphery metric of Borgatti and Everett that capture patterns of peripheral dependency and, optionally, core dominance. As with the original metric of Borgatti and Everett, the extensions can be used either to measure the degree of powerrelational patterns in pre-given core-periphery partitions or as part of a criteria function for finding such

as such transforming the system into a "class system" (1966a, p. 146). In blockmodeling terms, this would then correspond to a cohesive subgroup block image. 
structures. Contrasting existing core-periphery metrics and heuristics, it is suggested, and demonstrated in the subsequent example section, that the proposed extensions are more suitable for analyzing coreperiphery structures where such power-relations are substantively relevant, within as well as outside its original international relations context, than what the standard core-periphery model allows for.

\section{Power-relational core-periphery models: peripheral dependency and core dominance}

This section proposes how the criteria for peripheral dependency and dominating cores can be operationalized as extensions to the intra-categorical density differential criterion. ${ }^{6}$ Starting with the standard core-periphery block image consisting of a dense core (a so-called 'complete block' in the intra-core section) and a sparse periphery (a 'null' block in the intra-periphery section) - see Figure 2 the criteria for peripheral dependency and core dominance are thus concerned with the patterns of ties in the off-diagonal blocks in Figure 2 below.

\section{\begin{tabular}{c|c|c|}
\multicolumn{1}{c}{} & \multicolumn{1}{c}{$\mathbf{C}$} & $\mathbf{P}$ \\
\cline { 2 - 3 } Core $(\mathbf{C})$ & com & - \\
\cline { 2 - 3 } Periphery (P) & - & nul \\
\cline { 2 - 3 } & &
\end{tabular}}

Figure 2: Ideal core-periphery blockimage (ignoring off-diagonal blocks) suggested by Borgatti and Everett (2000, p. 383)

The core-periphery metric of Borgatti and Everett (2000) corresponds to a correlation between observed and ideal values, where values in the intra-core and intra-periphery blocks are correlated with, respectively, ones and zeros, optionally also correlating values in each of the inter-categorical sections with a pre-specified "density". ${ }^{7}$ The herein proposed extensions ${ }^{8}$ to this metric supplement the sets of observed and ideal values for the intra-categorical blocks with additional value-pairs for observed and ideal tie patterns in the inter-categorical blocks.

For directional networks, dependency and dominance are directional concepts. Outbound peripheral dependency and inbound core dominance are identified by examining periphery-to-core ties, whereas inbound dependency and outbound dominance are found in the core-to-periphery block in Figure 2. Which of these power-relational features to include depends on the theoretical significance and interpretational meaning of dependency and dominance in the particular context of the analyzed network and, of course, whether the network is directional or not.

\footnotetext{
${ }^{6} \mathrm{~A}$ demonstrational Windows client that implements (using local optimization) the proposed extensions to the Borgatti-Everett metric can be found at http://www.carlnordlund.net/

${ }^{7}$ As implemented in Ucinet (version 6.598), the inter-categorical "density" parameters in the Borgatti-Everett metric are not densities in the traditional binary blockmodeling sense; rather, similar to the case for the intracategorical correlations, the values in the inter-categorical blocks are correlated to the specified "density" parameters. For instance, in the case of an inter-categorical block with a chequered binary patterns with alternating 1 - and 0 -cells, i.e. a block density of 0.5 , setting the Ucinet parameters to 0.5 implies that each of the empirical ones and zeros are correlated to 0.5 , vastly reducing the overall core-periphery fit in this case.

${ }^{8}$ As with the original Borgatti-Everett metric, the specifications that follow are restricted to single-layer, one-mode networks.
} 


\section{Peripheral dependency}

In the dependency and world-system perspective, the notion of peripheral dependency is part and parcel of the core-periphery concept. As reflected in Galtung's specification, the defining feature of a peripheral actor is being monopolized by a singular core actor and lacking ties to other actors. Expressed as an ideal block type as used in generalized blockmodeling, outbound peripheral dependency translates into a so-called 'row-functional' block in the periphery-to-core block (see, e.g., Doreian, Batagelj, \& Ferligoj, 2005, p. 213), i.e. where there is exactly one tie in each row of the block. For inbound peripheral dependency, this procedure is done with respect to the columns in the core-to-periphery block (i.e. a so-called 'column-functional' block in generalized blockmodeling terminology).

In order to capture peripheral dependency, the total lists of observed and ideal values for the intracategorical blocks are supplemented with value-pairs for the inter-categorical blocks. ${ }^{9}$ For outbound peripheral dependency, each row in in the periphery-to-core block (see Figure 2) is first sorted. The largest value in each of these rows are correlated with unity whereas the remaining values are correlated with zero. ${ }^{10}$ If a block row contains two or more ties with the same maximum tie value, a likely scenario in binary networks, only one of these values are correlated to unity and remaining with zero. ${ }^{11}$ For inbound peripheral dependency, the corresponding procedure is done with respect to block columns in the core-to-periphery block.

\section{Core dominance}

Mirroring peripheral dependency, the dependency and world-system traditions characteristically depict the core as dominating the periphery. This is reflected in the visual example provided by Galtung (1971), where each of the core actors are dominating exclusive sets of peripheral actors. However, as reflected in the overall peripheral focus of the dependency school, it is conceivable that core actors could be nondominating, i.e. where the relatively high intra-core density constitutes the sole defining topological feature of core actors. Inclusion of core dominance as a criterion for power-relational core-periphery could thus be deemed optional to peripheral dependency, depending on the specifics of the research question that motivates a power-relational core-periphery analysis.

As core dominance implies having a variable number of ties with peripheral actors, translating this criterion to the correlation-based Borgatti-Everett metric is not as straight-forward as is the case for

\footnotetext{
${ }^{9}$ Although not explored here, an alternative is to calculate separate correlations for, respectively, inter- and intracategorical sections, using the latter as an outgoing stat rather than part of the criteria function.

${ }^{10} \mathrm{An}$ example of the calculation procedure for peripheral dependency and core dominance is given in the toy examples below.

${ }^{11}$ In cases where a presumed peripheral actor lacks ties to any of the presumed core actors, this means that one of these missing ties $(0)$ is correlated to unity, whereas the remaining missing ties are correlated to zero. Although not explored here, a more 'penalizing' alternative is to correlate all these missing ties to unity.
} 
peripheral dependency. To check whether the criterion for inbound core dominance is fulfilled ${ }^{12}$, it is only necessary to examine the largest value in respective block column and, similar to the peripheral dependency criterion, correlate these values with unity. However, whereas the criteria for dense cores, sparse peripheries and peripheral dependency stipulates that all values in respective block are included in the correlation, the criterion for core dominance would have a much lower influence on the final correlation measure than what these other criteria would have. Addressing this, the suggested extension to the Borgatti-Everett metric for capturing core dominance is designed somewhat differently. For inbound core dominance, the highest value in each block column of the periphery-to-core block is obtained, a value that is correlated to unity not only once, but repeatedly for as many rows (i.e. peripheries) as there are in the particular partition.

\section{A composite metric of power-relational core-periphery structures: combining intra- and inter- categorical criteria}

As the default Borgatti-Everett metric is a correlation of value-pairs from the two diagonal block sections (see Figure 2), it depends on the relative contribution of value-pairs from respective block. In the default version of the metric, the total number of value-pairs and the relative contributions from the two intra-categorical sections depend on the relative sizes of respective category. The amount and distribution of value-pairs for a directional 20-actor network is given in Figure 3 below.

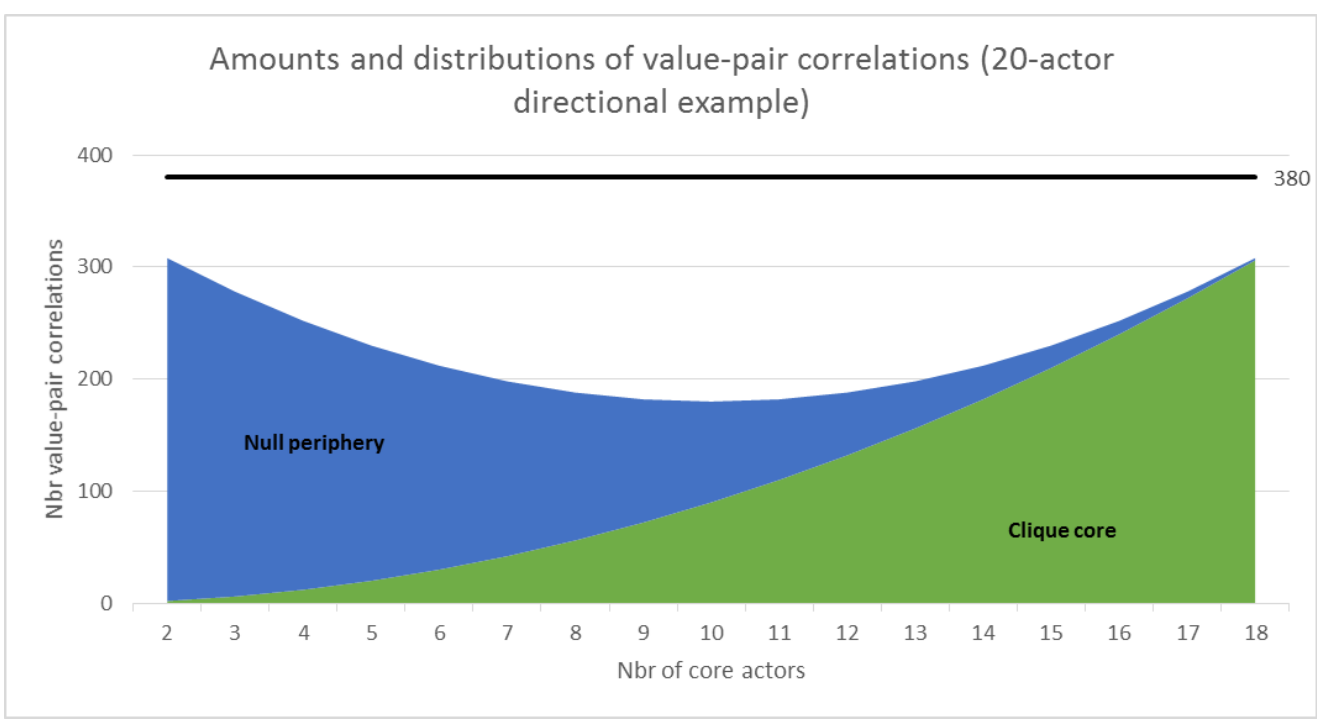

Figure 3: Amount and distribution of value-pair correlations for a directional 20-actor network (without self-ties)

If we were to extend this metric with two power-relational criteria, the number of total value-pair correlations becomes equal to the number of possible ties in the network, irrespective of the relative sizes of respective category. For a directional 20 -actor network, this corresponds to the top black line in

12 Expressed as ideal block types in generalized blockmodeling, inbound and outbound core dominance corresponds to, respectively, a column-regular block in the periphery-to-core ties and a row-regular block in the core-to-periphery ties (see (Doreian, Batagelj, \& Ferligoj, 2005, p. 213) 
Figure 3 above. However, when including one, three or four criteria for dependency and dominance, the relative influences of intra- and inter-categorical correlations change and once again depend on relative cluster sizes. For instance, when only including outbound peripheral dependency in a directional network, only value-pairs for the periphery-to-core block is included. If we instead were to include all four power-relational criteria, each cell in both off-diagonal blocks are counted twice, biasing the final correlation in favor of power-relational patterns over the density differential criteria.

To keep the relative influence of block sections independent from the number of chosen power-relational criteria, the standard correlation coefficient formula used in the default Borgatti-Everett metric is replaced by its weighted version ${ }^{13}$. Thus, in addition to the two vectors with observed and ideal patterns, a third vector with weights for respective value-pair is included, using the formula for weighted correlation coefficient as follows:

$r_{w}=\frac{\sum w_{i}\left(x_{i}-\bar{x}\right)\left(y_{i}-\bar{y}\right)}{\sum w_{i} \sqrt{\sum w_{i}\left(x_{i}-\bar{x}\right)^{2} \cdot \sum w_{i}\left(y_{i}-\bar{y}\right)^{2}}}$

where $x_{i}$ and $y_{i}$ are, respectively, the observed and ideal values, $w_{i}$ is the weight for that value pair, and where the weighted means are $\bar{x}=\sum w_{i} x_{i} / \sum w_{i}$ and $\bar{y}=\sum w_{i} y_{i} / \sum w_{i}$.

For the value-pairs representing the observed and ideal ties within the core and periphery, respectively, their weights $\left(w_{\text {intra }}\right)$ are always set to unity. For value-pairs representing ties between core and periphery, i.e. the inter-categorical ties checked by the dependency and dominance criteria, their weights ( $w_{\text {inter }}$ ) depend on the number of critieria included in the analysis. For directional networks, setting $w_{\text {inter }}$ to 2 divided by the number of power-relational criteria means that the relative influence of each potential tie on the final correlation remains the same, irrespective of the number of criteria. For symmetric networks, a single power-relational criterion should be weighted with unity whereas the value-pair weights should be set to 0.5 when both dependency and dominance are included. Suggested settings for $w_{\text {inter }}$ for different number of power-relational criteria are given in Table 1 below.

\footnotetext{
${ }^{13}$ Other options exist for combining the intra- and inter-categorical criteria. One such option, tentatively explored in the scope of this research project, is to calculate separate correlations for respective set of criteria, subsequently ombining them using a Cobb-Douglas-type of utility function. A would-be theoretical advantage with separate correlations for intra- and inter-categorical criteria is that each have their own distinct mean values. This seemed to be particularly useful for valued networks where the values of core-periphery ties often seem to be lower than intra-core ties. An additional advantage is that a criteria function can be constructed with marginal rates of substitution (such as the Cobb-Douglas function), i.e. where a bad fit with respect to dependency and dominance cannot be fully compensated by a high-scoring intra-categorical density differential.
} 


\begin{tabular}{|c|c|c|c|}
\hline \multicolumn{2}{|c|}{ Symmetric networks } & $w_{\text {inter }}$ & $w_{\text {intra }}$ \\
\hline \multicolumn{2}{|c|}{ Dependency OR dominance } & 1 & \multirow{7}{*}{1} \\
\hline \multicolumn{2}{|c|}{ Dependency AND dominance } & 0.5 & \\
\hline \multicolumn{3}{|c|}{ Directional networks } & \\
\hline \multirow{4}{*}{$\begin{array}{l}\text { Number of } \\
\text { power-relational } \\
\text { criteria }\end{array}$} & 1 (e.g. only outbound dependency) & 2 & \\
\hline & 2 (e.g. in- and outbound dependency) & 1 & \\
\hline & 3 & $2 / 3$ & \\
\hline & 4 (in- and outbound dependency and dominance) & 0.5 & \\
\hline
\end{tabular}

Table 1: Suggested weights for power-relational (inter-categorical) criteria

\section{Examples}

In this section, the proposed extensions to the Borgatti-Everett metric are applied to a set of example networks, comparing obtained partitions and criteria scores with those resulting from the default Borgatti-Everett heuristic. Beginning with three smaller examples, one which demonstrates the details of the calculation of dependency and dominance, this is followed by an analysis of the binary and valued journal citation data in (Borgatti \& Everett, 2000; from Baker, 1992). Circling back to the political economy genesis of core-periphery thinking, the example section is rounded off by analyzing the network of European commodity trade in 2010 (Nordlund, 2016)

\section{Toy examples: BEfig1, Galtung, Intercontinental trade}

The first of the three smaller networks is the 10-actor network used by Borgatti and Everett (2000, p. 377; Figure 1) to exemplify an ideal core-periphery structure. With its intra-core clique and disconnected peripheries, all cores have ties to peripheral actors (i.e. core dominance) but two out of the six peripheral actors have ties to two core actors (i.e. not ideal peripheral dependency). The second example is the one provided by Galtung (1971). With ideal inter-categorical patterns of dependency and dominance and a lack of intra-peripheral ties, intra-core relations constitute an imperfect clique. Expanding into valued and directional networks, the third example is a 7-actor directional network of aggregate commodity trade in the 1995-1999 period between seven world regions: North and Latin America, Asia, Africa, Australasia, and Western and Eastern Europe. This example also serves to demonstrate how the correlation coefficient is calculated for dependency and dominance. For each of these examples, the optimal solution found by the default Borgatti-Everett metric is compared with those obtained when including, respectively, dependency, and both dependency and dominance.

In the core-periphery example provided by Borgatti and Everett (2000, p. 377) - see Table 2 below - the intuitive core consists of actors 1-4. With these actors constituting an ideal clique and remaining actors disconnected from each other, the default Borgatti-Everett finds this partition to be the optimal, and ideal, solution. Adding peripheral dependency, the same core is still found, though the non-dependency of actors 5 and 8 yields a slightly less ideal score. When including both dependency and dominance, 
switching to the weighted correlation coefficient formula with a $w_{\text {inter }}$ set to 0.5 (see Table 1 above), the observed dominance for actors 1-4 is rewarded by an increased score.

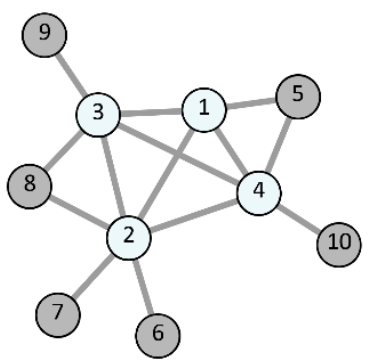

\begin{tabular}{l|c|c} 
BEfig1 [Binary, Symmetric] & Correlation & Core actors \\
\hline Default BE & 1 & \\
\cline { 1 - 2 } Default BE + dependency & 0.897 & \multirow{2}{*}{$1,2,3,4$} \\
\cline { 1 - 2 } Default BE + dependency + dominance & 0.956 & \\
\hline
\end{tabular}

Table 2: Core-periphery example provided by Borgatti and Everett (2000, p. 377)

As previously observed, Galtung's so-called "feudal interaction structure" has an intuitive core that corresponds to a less-than-ideal clique. Although the default Borgatti-Everett metric finds this intuitive core, the correlation is less-than-ideal - see Table 3 below. Adding peripheral dependency, subsequently also core dominance, the same intuitive core is found, with incrementally increasing scores.

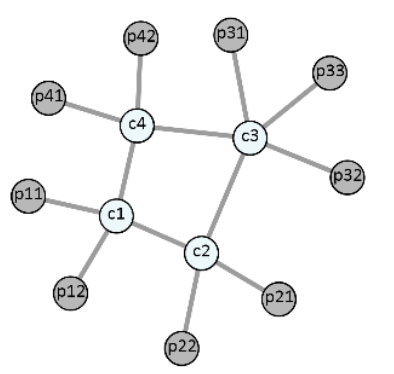

\begin{tabular}{l|c|c|} 
Galtung [Binary, Symmetric] & Correlation & Core actors \\
\hline Default BE & 0.795 & \\
\cline { 1 - 2 } Default BE + dependency & 0.917 & \multirow{2}{*}{$\mathrm{c} 1, \mathrm{c} 2, \mathrm{c} 3, \mathrm{c} 4$} \\
\hline Default BE + dependency + dominance & 0.945 & \\
\hline
\end{tabular}

Table 3: Galtung's core-periphery example (Galtung, 1971, p. 89)

The final toy network consists of commodity trade between seven world regions, aggregated using Comtrade data for the 1995-1999 period (see Nordlund, 2010, p. 98). In Table 4 below, the data matrix is blocked into a hypothetical partition where Asia, North America and Western Europe constitute a hypothetical core. Optimal correlations and their corresponding partitions for the default BorgattiEverett metric and the two power-relational extensions are found in Table 5.

\begin{tabular}{|c|c|c|c|c|c|c|c|}
\hline & \multicolumn{3}{|c|}{ Core } & \multicolumn{4}{|c|}{ Periphery } \\
\hline & ASI & NAM & WEU & AFR & AUS & EEU & LAT \\
\hline ASI & & 358 & 263 & 16 & 27 & 16 & 31 \\
\hline NAM & 226 & & 185 & 10 & 17 & 9 & 133 \\
\hline WEU & 239 & 201 & & 38 & 19 & 109 & 50 \\
\hline AFR & 15 & 13 & 38 & & 0 & 1 & 3 \\
\hline AUS & 40 & 8 & 10 & 1 & & 1 & 1 \\
\hline EEU & 20 & 10 & 100 & 2 & 0 & & 2 \\
\hline LAT & 26 & 141 & 41 & 2 & 1 & 3 & \\
\hline
\end{tabular}

Table 4: Aggregate intercontinental commodity trade 1995-1999 (billion USD) 


\begin{tabular}{l|c|l}
\multicolumn{1}{c}{ Intercont. trade [Valued, Directional] } & Correlation & \multicolumn{1}{c}{ Core actors } \\
\hline Default BE & 0.975 & NAM, WEU \\
\hline Default BE + dependency & 0.754 & ASI, NAM, WEU \\
\hline Default BE + dependency + dominance & 0.801 & NAM, WEU \\
\hline
\end{tabular}

Table 5: Core-periphery results for the intercontinental trade example (the dependency and dominance criteria are both in-as well as outbound)

At the optimal correlation of 0.975, the default Borgatti-Everett metric finds the optimal core to consist of North America and Western Europe. This is despite the fact that the flows between Asia and, respectively, North America and Western Europe represent the four largest dyads in the network. This is primarily due to intra-core variance: by placing Asia in the periphery, only the two relatively similar bilateral flows between North America and Western Europe are correlated with unity. Additionally, as Asia has relatively weak ties with the identified peripheral regions, i.e. a seemingly low degree of dominance, placing Asia in the periphery has only a marginal effect on intra-peripheral variance.

Adding in- and outbound peripheral dependency, the two significant Asian trading ties to North America and Western Europe imply non-dependence: keeping Asia in the periphery with the dependency criteria results in the low correlation of 0.536 . Rather, the optimal solution (0.754) with the in- and outbound dependency criteria is found when Asia joins the core. However, when also adding the core dominance criteria, the relatively weak ties between Asia and, respectively, Africa, Australasia, Eastern Europe and Latin America (see Table 4 above) once again places Asia in the periphery, this time at a correlation of 0.801 .

To exemplify the calculation procedure, correlations for the various criteria are calculated for the hypothetical partition in Table 4. Although this particular partition was only found when extending the default metric with peripheral dependency only, the correlations for all three varieties of the metric are calculated ${ }^{14}$. The three sections in Table 6 below contain the value-pairs to be correlated for the different criteria, where the weights of the value-pairs for peripheral dependency and core dominance depend on the number of criteria included (see Table 1 above). Results for the various metrics for this particular partition is given in Table 7 .

\footnotetext{
${ }^{14}$ In a local optimization search algorithm (such as implemented in the demonstrational software client accompanying this article), the algorithm calculates the correlations for neighboring partitions, i.e. partitions where either one actor is moved between clusters or two actors in different clusters are swapped with each other, repeating the exploration for the partition(s) that results in a higher correlation. For this small network, an exhaustive search was instead performed, i.e. examining all possible core-periphery partitions.
} 


\begin{tabular}{|c|c|c|c|}
\hline & \multicolumn{3}{|c|}{$\begin{array}{l}\text { Default Borgatti-Everett } \\
\text { Value-pair weights: } 1\end{array}$} \\
\hline & Dyad & Value & Model \\
\hline \multirow{6}{*}{ 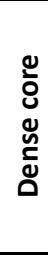 } & ASI-NAM & 358 & 1 \\
\hline & ASI-WEU & 263 & 1 \\
\hline & NAM-ASI & 226 & 1 \\
\hline & NAM-WEU & 185 & 1 \\
\hline & WEU-ASI & 239 & 1 \\
\hline & WEU-NAM & 201 & 1 \\
\hline \multirow{12}{*}{ 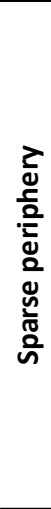 } & AFR-AUS & 0 & 0 \\
\hline & AFR-EEU & 1 & 0 \\
\hline & AFR-LAT & 3 & 0 \\
\hline & AUS-AFR & 1 & 0 \\
\hline & AUS-EEU & 1 & 0 \\
\hline & AUS-LAT & 1 & 0 \\
\hline & EEU-AFR & 2 & 0 \\
\hline & EEU-AUS & 0 & 0 \\
\hline & EEU-LAT & 2 & 0 \\
\hline & LAT-AFR & 2 & 0 \\
\hline & LAT-AUS & 1 & 0 \\
\hline & LAT-EEU & 3 & 0 \\
\hline
\end{tabular}

\begin{tabular}{|c|c|c|c|}
\hline & \multicolumn{3}{|c|}{$\begin{array}{l}\text { Peripheral dependency } \\
\text { Value-pair weights: } 2 / C\end{array}$} \\
\hline & Dyad & Value & Model \\
\hline \multirow{12}{*}{ 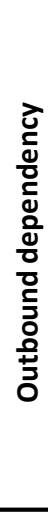 } & AFR-ASI & 15 & 0 \\
\hline & AFR-NAM & 13 & 0 \\
\hline & AFR-WEU & 38 & 1 \\
\hline & AUS-ASI & 40 & 1 \\
\hline & AUS-NAM & 8 & 0 \\
\hline & AUS-WEU & 10 & 0 \\
\hline & EEU-ASI & 20 & 0 \\
\hline & EEU-NAM & 10 & 0 \\
\hline & EEU-WEU & 100 & 1 \\
\hline & LAT-ASI & 26 & 0 \\
\hline & LAT-NAM & 141 & 1 \\
\hline & LAT-WEU & 41 & 0 \\
\hline \multirow{12}{*}{ 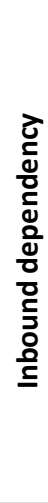 } & ASI-AFR & 16 & 0 \\
\hline & NAM-AFR & 10 & 0 \\
\hline & WEU-AFR & 38 & 1. \\
\hline & ASI-AUS & 27 & 1 \\
\hline & NAM-AUS & 17 & 0 \\
\hline & WEU-AUS & 19 & 0 \\
\hline & ASI-EEU & 16 & 0 \\
\hline & NAM-EEU & 9 & 0 \\
\hline & WEU-EEU & 109 & 1 \\
\hline & ASI-LAT & 31 & 0 \\
\hline & NAM-LAT & 133 & 1 \\
\hline & WEU-LAT & 50 & 0 \\
\hline
\end{tabular}

\begin{tabular}{|c|c|c|c|}
\hline & \multicolumn{3}{|c|}{ Core dominance } \\
\hline & Dyad & Value & Model \\
\hline \multirow{12}{*}{ 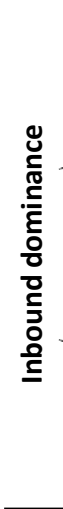 } & AUS-ASI & 40 & 1 \\
\hline & (AFR-ASI) & 40 & 1 \\
\hline & (EEU-ASI) & 40 & 1 \\
\hline & (LAT-ASI) & 40 & 1 \\
\hline & LAT-NAM & 141 & 1 \\
\hline & (AFR-NAM) & 141 & 1 \\
\hline & (AUS-NAM) & 141 & 1 \\
\hline & (EEU-NAM) & 141 & 1 \\
\hline & EEU-WEU & 100 & 1 \\
\hline & (AFR-WEU) & 100 & 1 \\
\hline & (AUS-WEU) & 100 & 1 \\
\hline & (LAT-WEU) & 100 & 1 \\
\hline \multirow{12}{*}{ 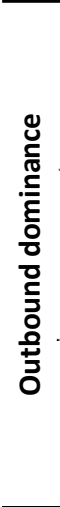 } & ASI-LAT & 31 & 1 \\
\hline & (ASI-AFR) & 31 & 1 \\
\hline & (ASI-AUS) & 31 & 1 \\
\hline & (ASI-EEU) & 31 & 1 \\
\hline & NAM-LAT & 133 & 1 \\
\hline & (NAM-AFR) & 133 & 1 \\
\hline & (NAM-AUS) & 133 & 1 \\
\hline & (NAM-EEU) & 133 & 1 \\
\hline & WEU-EEU & 109 & 1 \\
\hline & (WEU-AFR) & 109 & 1 \\
\hline & (WEU-AUS) & 109 & 1 \\
\hline & (WEU-LAT) & 109 & 1 \\
\hline
\end{tabular}

Table 6: Value-pair correlations for the directional intercontinental trade example (C=Number of included power-relational criteria)

\begin{tabular}{l|c|c|c}
\multicolumn{1}{c}{ Intercont. trade [Valued, Directional] } & \multicolumn{1}{c}{$w_{\text {inter }}$} & Correlation & $\begin{array}{c}\text { Core } \\
\text { actors }\end{array}$ \\
\hline Default BE & $\mathrm{n} / \mathrm{a}$ & $0.962^{*}$ & ASI, \\
\hline Default BE + dependency (in/out) & 1 & 0.754 & NAM, \\
\hline Default BE + dependency + dominance (both in/out) & 0.5 & $0.706^{*}$ & WEU \\
\hline
\end{tabular}

Table 7: Core-periphery metrics for the intercontinental trade example with Asia, North America and Western Europe as the hypothetical core (*: non-optimal solutions for this partition)

The table with value-pairs for the peripheral dependency criteria demonstrates how only the largest tie a presumed peripheral actor has with the presumed core actors is correlated with unity, whereas the remaining ties to the other core actors are correlated with zero. For core dominance, the largest tie a presumed core has with the presumed peripheral actors is correlated with unity, repeating this correlation for the number of peripheries that exist. As can be seen in the right-hand part in Table 6, the dominance of Asia with respect to the peripheries in this partition is weaker than the dominance of North America (with respect to Latin America) and Western Europe (with respect to Eastern Europe).

The ideal power-relational core-periphery model is thus not static, but the specific values that are correlated with unity depend on the pattern and strength of core-periphery ties. This allows for identifying the specific ties that are the potential ties of dependency and dominance. For the partition given in Table 4, Table 6 and Table 7 above, i.e. the optimal solution when extending the default metric 
with peripheral dependency, the ties of dependency are between Africa and Western Europe, East and West Europe, and North and Latin America, and, to a lesser extent, Asia's ties to Australasia and Latin America.

\section{Example: Baker journal citation data}

In his study of citation clusters among social work journals, Baker (1992) collected data on number of citations within and between 20 journals for the years 1985-86. This and subsequent analyses (Borgatti \& Everett, 2000; Nordlund, 2016) found this network to correspond to a core-periphery structure. In Borgatti and Everett (2000), the original Baker data was (max-)symmetrized and self-ties excluded before demonstrating their suggested correlation-based metric on both the binary and valued versions of the data. For comparative purpose, the analyses below uses the identical binary and valued data ${ }^{15}$ as that used by Borgatti and Everett (2000, p. 386).

\section{Binary citation data}

Aplying the default Borgatti-Everett heuristic on the binary citation data, the optimal solution (at a correlation of 0.860 ) consists of a 7-journal core - see Figure 4 (solid-line partition). Adding the peripheral dependency criteria, the optimal solution places ASW in the core: although ASW lacks ties with two presumed core journals, its remaining five core ties makes it a weak peripheral candidate. In this solution, the non-dependence of all but three peripheral journals do however bring the correlation down to 0.686 when including the peripheral dependency criteria.

\footnotetext{
${ }^{15}$ As noted in Nordlund (2016, p. 168), the symmetrization in Borgatti \& Everett (2000, p. 386) of the original data (Baker, 1992, p. 159) contains a few errors. For comparative reasons, the current paper nevertheless uses the exact same (yet imperfectly max-symmetrized) data as used by Borgatti \& Everett (2000).
} 


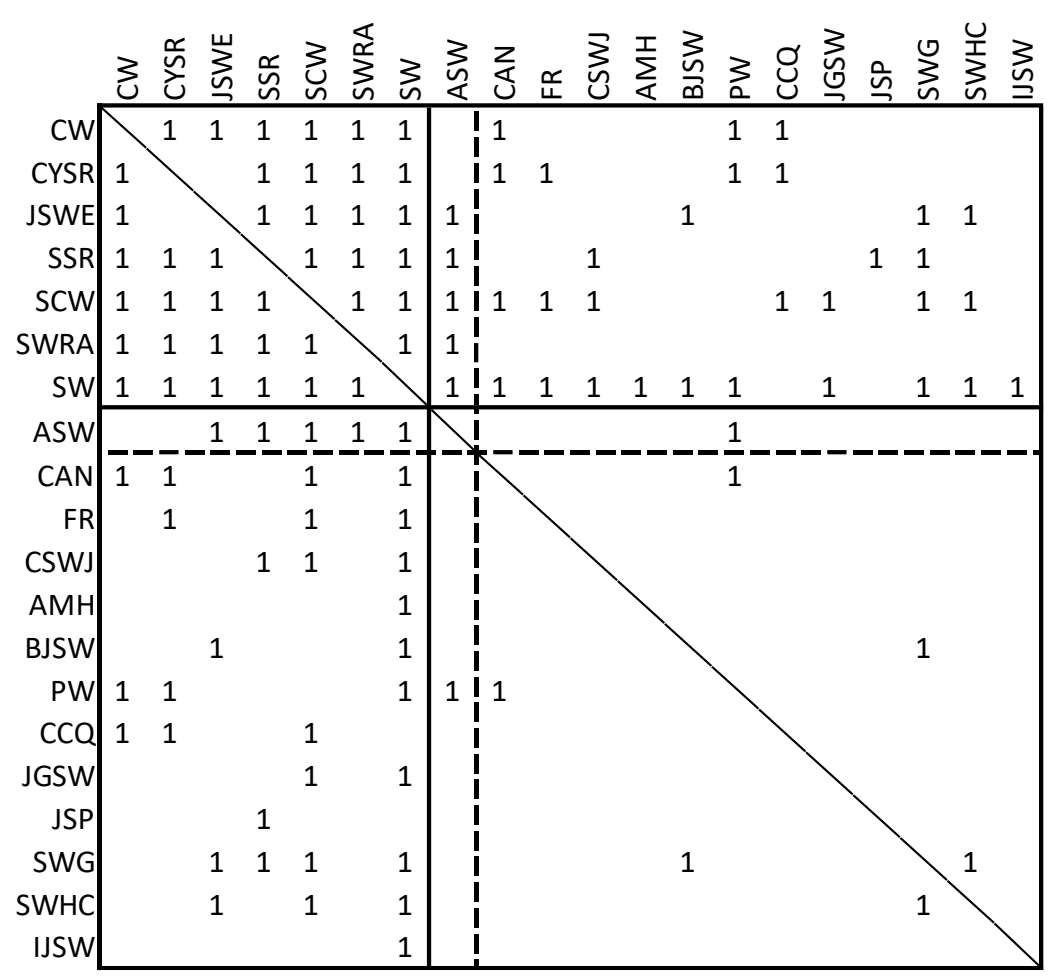

Figure 4: Optimal core-periphery solution for (binary) Baker citation data (dashed partition lines: peripheral dependency; solid partition lines: default Borgatti-Everett, and with both peripheral dependency and core dominance)

When also adding core dominance, the optimal solution (0.838) is the same as that for the default Borgatti-Everett metric, i.e. with ASW placed in the periphery. With ASW in the periphery, SWRA is provided with a peripheral journal to dominate. Although the multiple core ties of ASW deviates from the ideal patterns of peripheral dependency, keeping ASW in the core would yield a significant reduction in the correlation (0.771) due to the non-dominance of SWRA.

Substantively, it can be questioned whether dependency on singular core journals constitute a characteristic feature of peripheral journals. Although peripheral journals indeed might have preferences regarding the core journals it refers to, distinctions that are lost when dichotomizing the valued network, there are no theoretical grounds for a peripheral journal to only cite articles in one core journal. Inbound core dominance, however, is arguably a more relevant criterion in the journal citation context, i.e. where core journals are not only characterized by citing each other, but also being cited by peripheral journals. Running the correlation-based heuristic with the core dominance ${ }^{16}$ criteria, i.e. excluding peripheral dependency, the same 7-journal core as in Figure 4 is found, at the very high correlation of 0.946 .

\section{Valued citation data}

This section analyzes the valued Baker citation network (Borgatti \& Everett, 2000, p. 386; see also Nordlund, 2016, p. 167), using the identical dataset as used by Borgatti and Everett (see footnote 15).

\footnotetext{
${ }^{16}$ As the data is symmetrized, both inbound and outbound core dominance is included. With non-symmetrized citation data, inbound core dominance is arguably a more relevant criterion for core journals than outbound core dominance (see also Doreian et al., 2005, p. 265ff)
} 
Applying the default Borgatti-Everett metric, the optimal solution (0.815) corresponds to a core of SSR, SW and SCW - see Figure 5 below.

Adding peripheral dependency, the core is supplemented with CSWJ and CW at the optimal correlation of 0.673 (dashed partition in Figure 5 below). For this solution, the largest core tie of a peripheral journal represents on average 70 percent of its total core journal citations, ties that on average are 145 percent higher than their second-largest core journal ties. The peripheral dependency criteria for the valued citation data thus seem to capture a preference of peripheral journals to cite specific core journals. Although most peripheral journals in this partition have their strongest connection with the core journal SW, the peripheral journals CAN (Child Abuse and Neglect), CCQ (Child Care Quarterly), and CYSR (Children and Youth Services Review) have their most prominent ties with the core journal CW (Child Welfare).

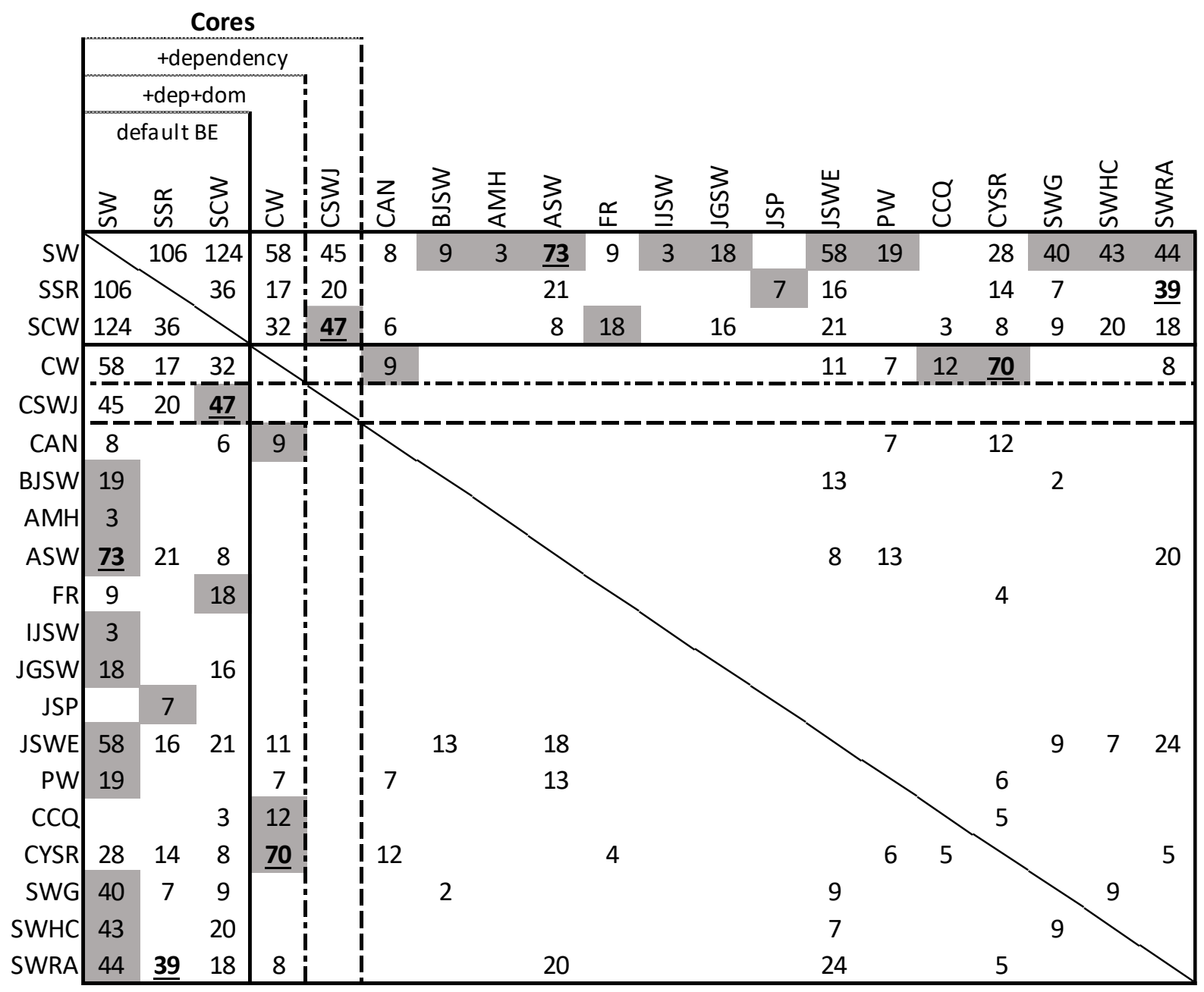

Figure 5: Optimal solutions for valued citation data using default and extended criteria (shaded cells: correlated with unity for dependency criteria; bold/underline values: correlated with unity for dominance criteria) 
Adding core dominance, the optimal solution (0.863) consists of the 4-journal core of SSR, SW, SCW and $\mathrm{CW}$ - see dash-line partition in Figure 5 above. Due to its lack of ties with peripheral journals in this partition, CSWJ is placed in the periphery.

Contrary to what was the case for the binary citation data, using core dominance as the only powerrelational criteria works less well for the valued citation data. Doing this results in an optimal solution with only SSR and SCW in the core: although this solution has a very high correlation (0.954), this is primarily due to the peripheral placement of SW where its very large ties with SSR and SCW are each correlated with unity 18 times for the core dominance criteria.

For the binary and valued Baker citation examples above, the suggested extensions to the BorgattiEverett metric seem to capture power-relational core-periphery models. The suitability of different criteria and combinations thereof do however seem to differ between the binary and valued versions of the data. Whereas different specializations among journals within a particular discipline could imply that peripheral journals more often cite particular core journals, the loss of such distinctions in the binary data makes peripheral dependency a less useful criterion. The core dominance criterion does however work well in the binary citation data. The opposite sems to be the case for the valued citation data. Whereas the criteria for peripheral dependency captures the patterns of peripheral preference for specific core journals, using the criteria for core dominance without peripheral dependency results in an arguably non-intuitive partition, where the seemingly most corelike journal SW is surprisingly placed in the periphery.

\section{International trade: EU/EFTA, 2010}

This example captures the total commodity trade (in billion USD) between 30 countries within EU and EFTA in 2010 (Nordlund, 2016, pp. 172, 177). Using the default Borgatti-Everett heuristic, the optimal solution (0.867) results in a core consisting of Germany, France, the Netherlands, Great Britain and Belgium.

Adding in- and outbound peripheral dependency, Italy and Spain join the "default" core in the optimal solution at a correlation of 0.686 . With both dependency and dominance, in- as well as outbound, the optimal coefficient (0.850) is obtained for a core consisting of Germany, France, and the Netherlands. All three solutions are indicated in Figure 6 below. 


\begin{tabular}{|c|c|c|c|c|c|c|c|c|c|c|c|c|c|c|c|c|c|c|c|c|c|c|c|c|c|c|c|c|c|c|}
\hline & \multicolumn{7}{|c|}{ Cores } & & \multirow[b]{5}{*}{$\stackrel{5}{4}$} & \multirow[b]{5}{*}{$\overrightarrow{0}$} & \multirow[b]{5}{*}{$\sum_{n}^{u}$} & \multirow[b]{5}{*}{ U } & \multirow[b]{5}{*}{$\begin{array}{l}\text { ơ } \\
\text { Z }\end{array}$} & \multirow[b]{5}{*}{$\underline{\underline{\underline{x}}}$} & \multirow[b]{5}{*}{ \} $&{\multirow[b]{5}{*}{\text { 兑 }}\text { 兑 }} &{\multirow[b]{5}{*}{\text { 홈 }}\text { 홈 }} &{\multirow[b]{5}{*}{\text { 总 }}\text { 总 }} &{\multirow[b]{5}{*}{\text { 른 }}\text { 른 }} &{\multirow[b]{5}{*}{\text { 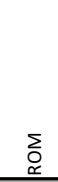 }}\text { 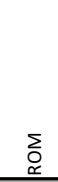 }} &{\multirow[b]{5}{*}{\text { ֶֻّ }}\text { ֶֻّ }} &{\multirow[b]{5}{*}{\text { 点 }}\text { 点 }} &{ } &{ } &{ } &{ } &{ } &{ } &{ } &{ } \\
{\hline} &{ } &{ } &{+\mathrm{de}} &{\text { oende }} &{ } &{ } &{ } &{ } &{ } &{ } &{ } &{ } &{ } &{ } &{ } &{ } &{ } &{ } &{ } &{ } &{ } &{ } &{ } &{ } &{ } &{ } &{ } &{ } &{ } &{ } \\
{\hline} &{ } &{ } &{\text { fault }} &{ } &{ } &{ } &{\text { i }} &{ } &{ } &{ } &{ } &{ } &{ } &{ } &{ } &{ } &{ } &{ } &{ } &{ } &{ } &{ } &{ } &{ } &{ } &{ } &{ } &{ } &{ } &{ } \\
{\hline} &{ } &{e p+d} &{ } &{ } &{ } &{ } &{\text { 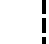 }} &{ } &{ } &{ } &{ } &{ } &{ } &{ } &{ } &{ } &{ } &{ } &{ } &{ } &{ } &{ } &{ } &{ } &{ } &{ } &{ } &{ } &{ } &{ } \\
{\hline} &{\text { 总 }} &{\text { 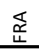 }} &{\text { 只 }} &{\begin{array}{l}\text { 㽣 } \\
\end{array}} &{\text { 亗 }} &{\leqq} &{\text { 岕 }} &{\text { 岌 }} &{ } &{ } &{ } &{ } &{ } &{ } &{ } &{ } &{ } &{ } &{ } &{ } &{ } &{ } &{\text { 奇 }} &{\begin{array}{l}\text { 임 } \\
\end{array}} &{\text { 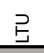 }} &{\text { 点 }} &{\text { 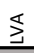 }} &{\bar{z}} &{\stackrel{5}{\Sigma}} &{\underline{\underline{\Xi}}} \\
{\hline \text { Germany (DEU) }} &{\text { 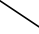 }} &{103} &{78} &{71} &{63} &{\underline{78}} &{37 i} &{56} &{59} &{38} &{27} &{32} &{10} &{5} &{21} &{17} &{10} &{10} &{9} &{10} &{7} &{4} &{5} &{3} &{3} &{1} &{1} &{1} &{0} &{0} \\
{\hline \text { France (FRA) }} &{82} &{ } &{19} &{36} &{\underline{43}} &{43} &{34} &{15} &{4} &{8} &{7} &{4} &{3} &{2} &{3} &{3} &{5} &{2} &{3} &{4} &{3} &{1} &{3} &{1} &{1} &{0} &{0} &{0} &{0} &{0} \\
{\hline \text { Netherlands (NLD) }} &{91} &{25} &{.} &{41} &{\underline{73} .} &{26 .} &{\text { 14. }} &{8 .} &{.4} &{6} &{-\underline{9}} &{4} &{3 .} &{3} &{4} &{.6 .} &{4} &{1 .} &{.4} &{2} &{3 .} &{1} &{1 .} &{.1} &{1} &{\underline{0} .} &{0} &{0 .} &{\underline{0}} &{0} \\
{\hline \text { Great Britain (GBR) }} &{51} &{26} &{29} &{\text { 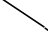 }} &{22} &{13} &{14} &{7} &{2} &{5} &{8} &{3} &{5} &{19} &{2} &{5} &{3} &{1} &{2} &{1} &{2} &{0} &{0} &{0} &{0} &{0} &{0} &{1} &{0} &{0} \\
{\hline \text { Belgium (BEL) }} &{45} &{\underline{47}} &{\underline{42}} &{26} &{1} &{18} &{8} &{5} &{2} &{4} &{6} &{2} &{1} &{1} &{2} &{3} &{2} &{1} &{2} &{1} &{2} &{0} &{5} &{0} &{1} &{0} &{0} &{0} &{0} &{0} \\
{\hline \text { Italy (ITA) }} &{\underline{58}} &{45} &{9} &{22} &{12} &{\text { 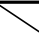 }} &{221} &{18} &{10} &{10} &{4} &{5} &{2} &{1} &{4} &{3} &{4} &{2} &{2} &{7} &{6} &{4} &{1} &{2} &{1} &{0} &{0} &{1} &{1} &{0} \\
{\hline \text { Spain (ESP) }} &{29} &{37} &{\underline{9}} &{15} &{-8 .} &{22} &{-i} &{5} &{2} &{-\frac{3}{-}} &{2} &{2} &{1} &{1} &{1} &{1} &{24} &{1} &{1 \frac{1}{-1}} &{1} &{2} &{1} &{0} &{0} &{\underline{0}} &{0} &{\underline{0}} &{0} &{-\underline{0}} &{\underline{0}} \\
{\hline \text { Switzerland (CHE) }} &{44} &{15} &{3} &{9} &{4} &{14} &{4} &{ } &{8} &{\overline{1}} &{1} &{1} &{1} &{1} &{1} &{1} &{0} &{0} &{1} &{1} &{1} &{1} &{0} &{\overline{0}} &{0} &{0} &{\overline{0}} &{0} &{0} &{0} \\
{\hline \text { Austria (AUT) }} &{45} &{6} &{2} &{4} &{2} &{11} &{2} &{8} &{\text { ( }} &{3} &{2} &{4} &{1} &{0} &{5} &{1} &{0} &{2} &{1} &{3} &{1} &{2} &{0} &{1} &{0} &{0} &{0} &{0} &{0} &{0} \\
{\hline \text { Poland (POL) }} &{38} &{9} &{6} &{9} &{4} &{10} &{4 !} &{1} &{3} &{\text { 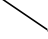 }} &{4} &{8} &{2} &{0} &{5} &{2} &{0} &{3} &{1} &{2} &{0} &{1} &{0} &{1} &{2} &{1} &{1} &{0} &{0} &{0} \\
{\hline \text { Sweden (SWE) }} &{18} &{7} &{7} &{10} &{7} &{5} &{31} &{1} &{2} &{3} &{\text { 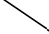 }} &{1} &{11} &{0} &{1} &{11} &{1} &{0} &{7} &{0} &{0} &{0} &{0} &{0} &{1} &{1} &{0} &{0} &{0} &{0} \\
{\hline \text { Czech rep (CZE) }} &{39} &{7} &{6} &{6} &{3} &{6} &{3} &{2} &{6} &{6} &{2} &{ } &{1} &{0} &{3} &{1} &{0} &{7} &{1} &{1} &{0} &{1} &{0} &{0} &{0} &{0} &{0} &{0} &{0} &{0} \\
{\hline \text { Norway (NOR) }} &{23} &{6} &{11} &{30} &{5} &{2} &{2} &{0} &{1} &{3} &{13} &{1} &{\text { 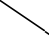 }} &{2} &{0} &{3} &{1} &{0} &{2} &{0} &{0} &{0} &{0} &{0} &{0} &{0} &{0} &{0} &{0} &{0} \\
{\hline \text { Ireland (IRL) }} &{19} &{8} &{5} &{20} &{20} &{4} &{4} &{6} &{1} &{1} &{2} &{1} &{1} &{ } &{0} &{1} &{1} &{0} &{1} &{0} &{1} &{0} &{0} &{0} &{0} &{0} &{0} &{0} &{0} &{0} \\
{\hline \text { Hungary (HUN) }} &{22} &{4} &{3} &{5} &{1} &{5} &{2} &{1} &{4} &{3} &{1} &{3} &{0} &{0} &{ } &{1} &{0} &{3} &{0} &{5} &{0} &{1} &{0} &{1} &{0} &{0} &{0} &{0} &{0} &{0} \\
{\hline \text { Denmark (DNK) }} &{15} &{4} &{4} &{6} &{1} &{3} &{2} &{1} &{1} &{2} &{12} &{1} &{5} &{1} &{1} &{ } &{0} &{0} &{2} &{0} &{1} &{0} &{0} &{0} &{0} &{0} &{0} &{0} &{0} &{0} \\
{\hline \text { Portugal (PRT) }} &{6} &{6} &{2} &{3} &{1} &{2} &{11} &{0} &{1} &{0} &{1} &{0} &{0} &{0} &{0} &{0} &{ } &{0} &{0} &{0} &{0} &{0} &{0} &{0} &{0} &{0} &{0} &{0} &{0} &{0} \\
{\hline \text { Slovakia (SVK) }} &{12} &{4} &{2} &{2} &{1} &{3} &{2} &{0} &{3} &{4} &{1} &{7} &{0} &{0} &{4} &{0} &{0} &{ } &{0} &{1} &{0} &{0} &{0} &{0} &{0} &{0} &{0} &{0} &{0} &{0} \\
{\hline \text { Finland (FIN) }} &{8} &{3} &{4} &{3} &{2} &{2} &{1} &{1} &{1} &{2} &{8} &{0} &{2} &{0} &{0} &{1} &{0} &{0} &{ } &{0} &{0} &{0} &{0} &{0} &{0} &{2} &{1} &{0} &{0} &{0} \\
{\hline \text { Romania (ROM) }} &{9} &{4} &{1} &{2} &{1} &{6} &{1} &{0} &{1} &{1} &{0} &{1} &{0} &{0} &{2} &{0} &{0} &{0} &{0} &{ } &{1} &{0} &{0} &{2} &{0} &{0} &{0} &{0} &{0} &{0} \\
{\hline \text { Greece (GRC) }} &{3} &{1} &{1} &{1} &{0} &{2} &{1} &{0} &{0} &{0} &{0} &{0} &{0} &{0} &{0} &{0} &{0} &{0} &{0} &{1} &{ } &{0} &{0} &{2} &{0} &{0} &{0} &{2} &{0} &{0} \\
{\hline \text { Slovenia (SVN) }} &{5} &{2} &{0} &{1} &{0} &{3} &{0} &{0} &{2} &{1} &{0} &{1} &{0} &{0} &{1} &{0} &{0} &{0} &{0} &{0} &{0} &{ } &{0} &{0} &{0} &{0} &{0} &{0} &{0} &{0} \\
{\hline \text { Luxembourg (LUX) }} &{4} &{2} &{1} &{1} &{3} &{1} &{1} &{0} &{0} &{0} &{0} &{0} &{0} &{0} &{0} &{0} &{0} &{0} &{0} &{0} &{0} &{0} &{ } &{0} &{0} &{0} &{0} &{0} &{0} &{0} \\
{\hline \text { Bulgaria (BGR) }} &{2} &{1} &{0} &{0} &{1} &{2} &{0} &{0} &{0} &{0} &{0} &{0} &{0} &{0} &{0} &{0} &{0} &{0} &{0} &{2} &{1} &{0} &{0} &{ } &{0} &{0} &{0} &{0} &{0} &{0} \\
{\hline \text { Lithuania (LTU) }} &{2} &{1} &{1} &{1} &{0} &{0} &{0 !} &{0} &{0} &{1} &{1} &{0} &{1} &{0} &{0} &{1} &{0} &{0} &{0} &{0} &{0} &{0} &{0} &{0} &{ } &{1} &{2} &{0} &{0} &{0} \\
{\hline \text { Estonia (EST) }} &{1} &{0} &{0} &{0} &{0} &{0} &{01} &{0} &{0} &{0} &{2} &{0} &{0} &{0} &{0} &{0} &{0} &{0} &{2} &{0} &{0} &{0} &{0} &{0} &{1} &{ } &{1} &{0} &{0} &{0} \\
{\hline \text { Latvia (LVA) }} &{1} &{0} &{0} &{1} &{0} &{0} &{0} &{0} &{0} &{0} &{1} &{0} &{0} &{0} &{0} &{0} &{0} &{0} &{0} &{0} &{0} &{0} &{0} &{0} &{1} &{1} &{ } &{0} &{0} &{0} \\
{\hline \text { Cyprus (CYP) }} &{0} &{0} &{0} &{0} &{0} &{0} &{0 !} &{0} &{0} &{0} &{0} &{0} &{0} &{0} &{0} &{0} &{0} &{0} &{0} &{0} &{1} &{0} &{0} &{0} &{0} &{0} &{0} &{ } &{0} &{0} \\
{\hline \text { Malta (MLT) }} &{0} &{0} &{0} &{0} &{0} &{0} &{01} &{0} &{0} &{0} &{0} &{0} &{0} &{0} &{0} &{0} &{0} &{0} &{0} &{0} &{0} &{0} &{0} &{0} &{0} &{0} &{0} &{0} &{ } &{0} \\
{\hline \text { Icel and (ISL) }} &{1} &{0} &{1} &{1} &{0} &{0} &{0} &{0} &{0} &{0} &{0} &{0} &{0} &{0} &{0} &{0} &{0} &{0} &{0} &{0} &{0} &{0} &{0} &{0} &{0} &{0} &{0} &{0} &{0} &{ } \\
$\hline}
\end{tabular}

Figure 6: Optimal solutions for EU/EFTA trade data using default and extended criteria (shaded cells: correlated with unity for dependency criteria; bold/underline values: correlated with unity for dominance criteria)

For the majority of peripheral countries, Germany constitute the premier partner, both with respect to their inbound and outbound flows. Germany constitute the largest source for Norwegian imports, but the largest Norwegian export flow goes to Great Britain. For the obtained solution when only dependency is included, Portugal is tightly knit to Spain, Malta primary imports from the core are Italian while its exports to the core primarily goes to France, and Ireland obtains most of its imports from Great Britain. Looking at the distribution of peripheral exports to the 7 core countries in this solution (dashed line in Figure 6), the largest export flows from a periphery to the core countries represents on average 39 percent of all exports to the core. However, the second largest core export flows from the peripheries constitute on average 21 percent of total core exports, a lower degree of peripheral dependency that is captured by the somewhat low correlation coefficient for outbound peripheral dependency (i.e. 0.677).

A more obvious reason for the relatively low correlation for peripheral dependency for this dataset is, of course, the skewed valued degree distribution of the actors in the dataset. Although the largest import flow to Iceland is lower than the smallest import flow to Germany, neither the default nor the extended Borgatti-Everett correlation-based metric takes such unequal relational capacities into account in their correlations. While a suitable transformation of the valued data could alleviate such 
differences prior to the identification of core-periphery structures, with or without power-relational criteria, such methodological endeavors are here left for future studies.

\section{Conclusion}

"Conceptions", Wallerstein argues (1974, p. 36), "precede and govern measurements". Exploring the history of the core-periphery concept and, particularly, its topological interpretations that followed in the post-war period, this paper found historical precedents for how core-periphery structures in contemporary network science is perceived, i.e. in terms of dense cores and sparse peripheries. However, this paper also found signficant support for the power-relational notions of peripheral dependency and core dominance as integral aspects of the classical core-periphery concept.

Building on the literature overview findings, this paper proposed how peripheral dependency and core dominance can be operationalized as extensions to the correlation-based metric of Borgatti and Everett (2000). Testing the extended metrics on a handful of example datasets, comparing how obtained partitions differ from those obtained when excluding power-relational patterns between core and peripheral actors, the proposed criteria and their operationalizations seem apt at capturing dependency and dominance. For the binary and valued Baker citation networks as well as the intra-European trade data, the criteria for dependency and dominance integrate well with the intra-categorical density differential criteria. However, when only including the core dominance criterion, the obtained coreperiphery partitions for the valued citation and trade networks seem non-intuitive. This could indicate that the herein suggested operationalization of core dominance is problematic, particularly with respect to valued networks.

The conventional network-scientific perception of what constitute a core-periphery structure is indeed a well-established concept that has proven, and continues to prove, its usefulness in a wide variety of network studies. However, for identifying peripheral dependency and core dominance, power-relational features that are intrinsically tied to the original core-periphery concept, this paper proposes alternative, power-relational core-periphery models that capture such patterns of core-periphery relations. Similar to how the original core-periphery concept disseminated across various disciplines, the applicability and theoretical significance of power-relational core-periphery models are not necessarily constrained within the context of international relations and political economy, but could equally have theoretical significance and applicability in vastly different types of networks and fields of study. 


\section{References}

Amin, S. (1976). Unequal development: An essay on the social formations of peripheral capitalism. New York: Monthly Review.

Baker, D. R. (1992). A structural analysis of social work journal network: 1985-1986. Journal of Social Service Research, 15(3-4), 153-168.

Bauer, P. T. (1954). West African Trade: A Study of Competition, Oligopoly, and Monopoly in a Changing Economy. A. M. Kelley.

Berman, B. J. (1974). Clientelism and neocolonialism: center-periphery relations and political development in African states. Studies in Comparative International Development (SCID), 9(2), $3-25$.

Borgatti, S. P., \& Everett, M. G. (2000). Models of core/periphery structures. Social Networks, 21(4), 375-395.

Borgatti, S. P., Everett, M. G., \& Johnson, J. C. (2013). Analyzing social networks. SAGE Publications Limited.

Bousquet, N. (2012). A variable geometry presiding over conceptualization. Routledge Handbook of World-Systems Analysis, 123.

Boyd, J. P., Fitzgerald, W. J., \& Beck, R. J. (2006). Computing core/periphery structures and permutation tests for social relations data. Social Networks, 28(2), 165-178.

Boyd, J. P., Fitzgerald, W. J., Mahutga, M. C., \& Smith, D. A. (2010). Computing continuous core/periphery structures for social relations data with MINRES/SVD. Social Networks, 32(2), $125-137$.

Breiger, R. L. (1981). Structures of economic interdependence among nations. Continuities in Structural Inquiry, 353-380.

Breiger, R. L., Boorman, S. A., \& Arabie, P. (1975). An algorithm for clustering relational data with applications to social network analysis and comparison with multidimensional scaling. Journal of Mathematical Psychology, 12(3), 328-383.

Cardoso, F. H., \& Faletto, E. (1967). Dependency and Development in Latin America (Berkeley, 1979); Andre Gunder Frank. Capitalism and Underdevelopment in Latin America, 30-31.

Chan, S. (1982). Cores and Peripheries Interaction Patterns in Asia. Comparative Political Studies, $15(3), 314-340$.

Chase-Dunn, C. K. (1998). Global formation: Structures of the world-economy. Rowman \& Littlefield.

Chase-Dunn, C. K., \& Grimes, P. (1995). World-systems analysis. Annual Review of Sociology, 387417.

Chase-Dunn, C. K., \& Hall, T. D. (1991). Core/periphery relations in precapitalist worlds. Westview Press.

Condliffe, J. B. (1951). The Commerce of Nations. Allen \& Unwin. 
Della Rossa, F., Dercole, F., \& Piccardi, C. (2013). Profiling core-periphery network structure by random walkers. Scientific Reports, 3.

Dominguez, J. I. (1971). Mice that do not roar: some aspects of international politics in the world's peripheries. International Organization, 25(2), 175-208.

Doreian, P., Batagelj, V., \& Ferligoj, A. (2005). Generalized Blockmodeling. Cambridge University Press.

Duvall, R. D. (1978). Dependence and dependencia theory: notes toward precision of concept and argument. International Organization, 32(01), 51-78.

Everett, M. G., \& Borgatti, S. P. (2000). Peripheries of cohesive subsets. Social Networks, 21(4), 397 407.

Frank, A. G. (1967). Capitalism and underdevelopment in Latin America (Vol. 93). NYU Press.

Galtung, J. (1966a). East-West interaction patterns. Journal of Peace Research, 146-177.

Galtung, J. (1966b, June). Small Groups Theory and the Theory of International Relations. Presented at the Lecture at the 75th Anniversary of the University of Chicago, Chicago.

Galtung, J. (1968). Small group theory and the theory of international relations: a study in isomorphism. New Approaches to International Relations, (7), 284-293.

Galtung, J. (1971). A structural theory of imperialism. Journal of Peace Research, 81-117.

Gills, B., \& Frank, A. G. (2014). The World System: Five Hundred Years Or Five Thousand? Routledge.

Gleditsch, N. P. (1967). Trends in world airline patterns. Journal of Peace Research, 4(4), 366-408.

Gochman, C. S., \& Ray, J. L. (1979). Structural Disparities in Latin America and Eastern Europe, 1950-1970. Journal of Peace Research, 16(3), 231-254.

Hojman, D. A., \& Szeidl, A. (2008). Core and periphery in networks. Journal of Economic Theory, 139(1), 295-309.

Janvry, A. de. (1975). The Political Economy of Rural Development in Latin America: An Interpretation. American Journal of Agricultural Economics, 57(3), 490-499.

Krugman, P. R. (1990). Increasing returns and economic geography. National Bureau of Economic Research.

Krugman, P. R. (1991). Geography and trade. MIT press.

Krugman, P. R. (1998). What's new about the new economic geography? Oxford Review of Economic Policy, 14(2), 7-17.

Lee, S. H., Cucuringu, M., \& Porter, M. A. (2014). Density-based and transport-based core-periphery structures in networks. Physical Review E, 89(3), 032810.

Lloyd, P., Mahutga, M. C., \& Leeuw, J. D. (2015). Looking Back and Forging Ahead: Thirty Years of Social Network Research on the World-System. Journal of World-Systems Research, 15(1), 4885 . 
Love, J. L. (1980). Raul Prebisch and the Origins of the Doctrine of Unequal Exchange. Latin American Research Review, 15(3), 45-72.

McKenzie, N. (1977). Centre and periphery: the marriage of two minds. Acta Sociologica, 20(1), 5574.

Meier, G. M., \& Baldwin, R. E. (1957). Economic Development: Theory, History, Policy. John Wiley \& Sons.

Mullins, N. C., Hargens, L. L., Hecht, P. K., \& Kick, E. L. (1977). The group structure of cocitation clusters: A comparative study. American Sociological Review, 552-562.

Muñiz, A. S. G., \& Carvajal, C. R. (2006). Core/periphery structure models: An alternative methodological proposal. Social Networks, 28(4), 442-448.

Nemeth, R. J., \& Smith, D. A. (1985). International trade and world-system structure: A multiple network analysis. Review (Fernand Braudel Center), 8(4), 517-560.

Nordlund, C. (2010). Social Ecography; International trade, network analysis, and an Emmanuelian conceptualization of ecological unequal exchange (Vol. 11). Department of Social and Economic Geography, Lund University. Retrieved from http://lup.lub.lu.se/record/1606296

Nordlund, C. (2016). A deviational approach to blockmodeling of valued networks. Social Networks, $44,160-178$.

Oman, C. P., \& Wignaraja, G. (1991). The postwar evolution of development thinking. Macmillan.

Prebisch, R. (1950). The Economic Development of Latin America and its Principal Problems. New York: United Nations, Dept. of Economic Affairs.

Rokkan, S., \& Urwin, D. W. (1983). Economy, territory, identity: Politics of West European peripheries. Sage Publications.

Rombach, M. P., Porter, M. A., Fowler, J. H., \& Mucha, P. J. (2014). Core-periphery structure in networks. SIAM Journal on Applied Mathematics, 74(1), 167-190.

Santos, T. dos. (1970). The Structure of Dependence. The American Economic Review, 60(2), 231-236.

Smith, D. A., \& White, D. R. (1992). Structure and Dynamics of the Global Economy: Network Analysis of International Trade 1965-1980. Social Forces, 70(4), 857-893.

Snyder, D., \& Kick, E. L. (1979). Structural position in the world system and economic growth, 19551970: A multiple-network analysis of transnational interactions. American Journal of Sociology, 1096-1126.

So, A. Y. (1990). Social Change and Development: Modernization, Dependency and World-System Theories. SAGE.

Vanolo, A. (2010). The border between core and periphery: Geographical representations of the world system. Tijdschrift Voor Economische En Sociale Geografie, 101(1), 26-36.

Wallerstein, I. (1974). The rise and future demise of the world capitalist system: concepts for comparative analysis. Comparative Studies in Society and History, 16(04), 387-415. 
Wallerstein, I. (1979). The Capitalist World-Economy. Cambridge University Press.

Wasserman, S., \& Faust, K. (1994). Social network analysis: Methods and applications (Vol. 8). Cambridge university press.

White, H. C., Boorman, S. A., \& Breiger, R. L. (1976). Social structure from multiple networks. I. Blockmodels of roles and positions. American Journal of Sociology, 730-780. 